Article

\title{
Investigation of a Resonant dc-dc Converter for Light Rail Transportation Applications
}

\author{
Bor-Ren Lin \\ Department of Electrical Engineering, National Yunlin University of Science and Technology, \\ Yunlin 640, Taiwan; linbr@yuntech.edu.tw; Tel.: +886-912-312-281
}

Received: 10 April 2018; Accepted: 24 April 2018; Published: 27 April 2018

\begin{abstract}
A high efficiency dc-dc converter is studied for light rail transportation applications on DC microgrid systems. The adopted structure includes two series-connected resonant circuits with single isolated transformer from input $750 \mathrm{~V}$ to output $48 \mathrm{~V}$. Two half-bridge resonant circuits and one voltage balance capacitor are used to reduce voltage rating of active devices and to realize split voltages balance. Two series resonant circuits are connected with input-series by single transformer to reduce primary root-mean-square currents. Therefore, power devices with low voltage rating are selected in studied circuit to reduce power loss on sower devices and transformer winding of the isolated transformer. Frequency control approach is adopted to adjust load voltage under different voltage condition and current variations. Since the equivalent resonant tank of the studied circuit is activated under inductive load, active devices are easily operated at zero-voltage switching over wide voltage and current operation range. The feasibility of the studied circuit has been verified with a $1 \mathrm{~kW}$ prototype.
\end{abstract}

Keywords: resonant circuit; zero-voltage switching; light rail transportation

\section{Introduction}

Renewable clean energy sources, wind energy, and solar photovoltaic (PV) energy, have been developed and researched to produce the clean energy to overcome the exhaustion of fossil fuels and electric vehicles and hybrid electric vehicles are developing to reduce environmental pollution and climbing temperature issues. Direct current (dc) microgrid systems have developed in order to incorporate energy storage systems, PV power, wind power, utility systems, local residential homes, and industrial factories with a common dc voltage. The dc bus voltage on the dc microgrid system can be 1500, 750, or $380 \mathrm{~V}$ for traction system, light rail transit, or residential building applications. Power transformers are widely employed to provide electrical isolation and voltage conversion levels. However, line frequency transformer [1,2] has a bulky size especially at traction and light rail applications. A high-performance dc-dc converter with high frequency and galvanic isolation is demanded as the interface between dc bus voltage and output voltage in light rail transportation vehicles. To prevent using low frequency transformer in traction and light rail applications, one possible solution is the transformerless converters [3-6] with series-parallel combination to reduce semiconductor blocking-voltage capability and current rating. The high frequency transformers are used in transformerless topologies to achieve electrical insulation demand. Conventional full-bridge dc-dc circuits use the insulated gate bipolar transistors (IGBT) devices with $1200 \mathrm{~V}$ voltage rating for high input voltage applications. Three-level converters [7-9] based on high frequency Metal-Oxide-Semiconductor Field-Effect Transistor (MOSFET) power semiconductors were widely used in modern power converters to overcome low frequency problem of IGBT-based full-bridge converters. Soft switching dc-dc converters [10-13] have been studied and presented to realize high efficiency power circuits. Phase-shift duty-cycle controls have been successfully used in 
full-bridge dc-dc converters to have the benefits of no switching loss at heavy load and low switching losses at light load. However, the low circuit efficiency and high circulating current loss at light load are the main disadvantages. Half-bridge resonant converters have the benefits of no switching loss for all power active devices and low reverse recovery loss for fast recovery diodes. However, half-bridge resonant converters are difficult to apply in high voltage input products. Full-bridge multilevel resonant circuit [13] was proposed to lessen voltage rating of power semiconductors and realize high efficiency converter. However, the control strategy is very difficult to implement using the general commercial integrated circuit with cost issue.

This paper studies a cascade resonant dc-dc circuit with a transformer for dc transportation vehicles. Due to series connection of two resonant circuits at input side, power semiconductors with low blocking-voltage and low turn-on resistance MOSFETs instead of Insulated Gate Bipolar Transistors (IGBTs) can be adopted to decrease conduction losses and lessen voltage rating of power active devices. Two half-bridge circuits are controlled with frequency modulation. The adopted series-connected resonant converter is operated under inductive load. Therefore, power active devices can be easily turned on under zero-voltage and fast recovery diodes are turned off under zero-current without reverse recovery current loss. Two half-bridge resonant circuits use the sane isolated transformer to lessen primary root-mean-square currents and conduction losses on active devices. The circuit schematic and system analysis are discussed in Section 2. The converter characteristics in steady state, design procedure and test results are discussed and presented in Section 3, followed by the conclusions.

\section{Proposed Circuit and System Operation}

The simplified circuit blocks in a dc microgrid system are shown in Figure 1 to combine clean energy sources, energy storage systems, utility systems, residential loads, and industrial applications. Ac-dc converters with bidirectional power flow are adopted between utility power and dc microgrid. Bidirectional dc-dc converter is adopted between dc microgrid and energy/power storage systems. For residential or commercial loads, unidirectional dc-dc converter or dc to ac converter is adopted to supply low dc voltage output or ac voltage output. The dc bus voltage in dc microgrid systems supplies $1500 \mathrm{~V}$ or $750 \mathrm{~V}$ for dc transportation systems and $380 \mathrm{~V}$ for local residential houses and industry factories. This study focused on dc-dc power converters for light rail transit systems. The dc microgrid for light rail applications is shown in Figure 2a. The input voltage $750 \mathrm{~V}_{\mathrm{dc}}$ is supplied from $\mathrm{dc}$ microgrid to conductor rail for power demand in each transportation vehicle. The simplified circuit diagrams of the distributed power in conventional transportation vehicles and trams. A dc-ac inverter is first used to convert input dc voltage into three-phase ac voltage. Second, an ac-dc converter converts ac voltage into low dc voltage for auxiliary power demand and an ac-dc-ac converter is adopted for ac motor drive. Figure $2 c$ shows the distributed power in the studied light rail transportation system. In this system, a dc-dc converter is directly converting $750 \mathrm{~V}$ voltage to supply auxiliary power in transportation vehicles. The dc-ac converters are adopted to drive AC motor and air and refrigerant compressors. In this way, the ac-dc converters are not necessary.

The circuit schematic of the developed converter for auxiliary circuit in light rail transportation system is given in Figure 3. Two half-bridge circuits by input-series output-parallel connected transformer is used in the studied converter. Since two resonant circuits are series connection, the voltage rating of power devices $Q_{1} \sim Q_{4}$ is reduced. The low turn-on resistance and high frequency operation of power semiconductors such as MOSFETs are selected to decrease conduction losses and reduce converter size. A voltage balance capacitor $C_{f}$ is adopted in order to balance $V_{C 1}$ and $V_{C 2}$. The resonant tanks $\left(L_{r 1}, C_{r 1}\right.$, and $\left.L_{m 1}\right)$ and $\left(L_{r 2}, C_{r 2}\right.$, and $\left.L_{m 2}\right)$ are resonant to help power active devices with zero-voltage switching and fast recovery diodes with zero-current switching. Thus, the power losses are reduced in the studied circuit. The driving signals of half-bridge circuits are based on frequency modulation to adjust AC voltage gain and to operate at inductive load. Figure 4 illustrates the main current and voltage signals in the studied circuit. The converter operation are based on the assumptions: (1) output capacitors $C_{01}$ and $C_{02}$ are larger enough to treat as the constant 
voltages; (2) $Q_{1} \sim Q_{4}, D_{1}$ and $D_{2}$ are all ideal; (3) $C_{r 1}=C_{r 2}, L_{r 1}=L_{r 2}$, and $L_{m 1}=L_{m 2} ;$ (4) $V_{C 1}=V_{C 2}$; and (5) the resonant tanks are operated at inductive load. Figure 5 demonstrates the topological circuits according to the conducting states of power devices under $f_{s w}$ (switching frequency) $<f_{r}$ (series resonant frequency). If $f_{s w}>f_{r}$, then only modes $1,3,4$, and 6 are operated in this region.

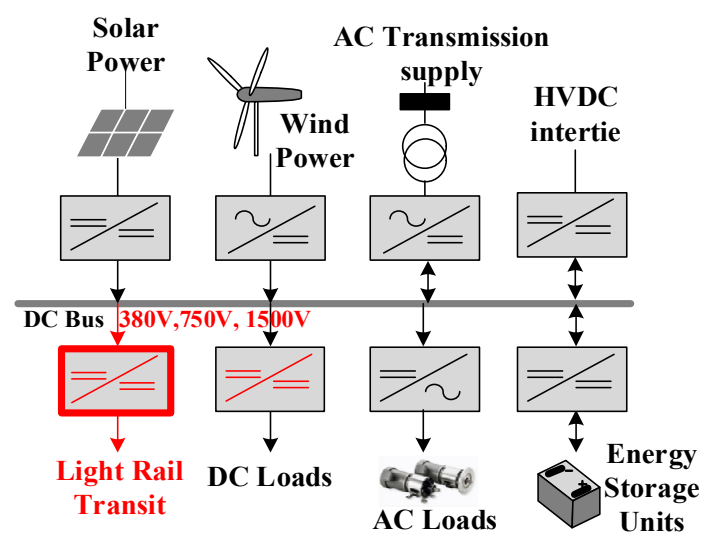

Figure 1. Simplified circuit schematic of a dc microgrid system.

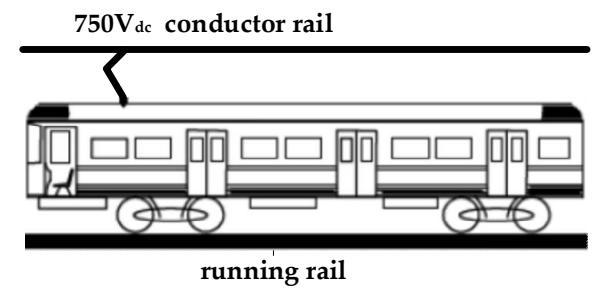

(a)

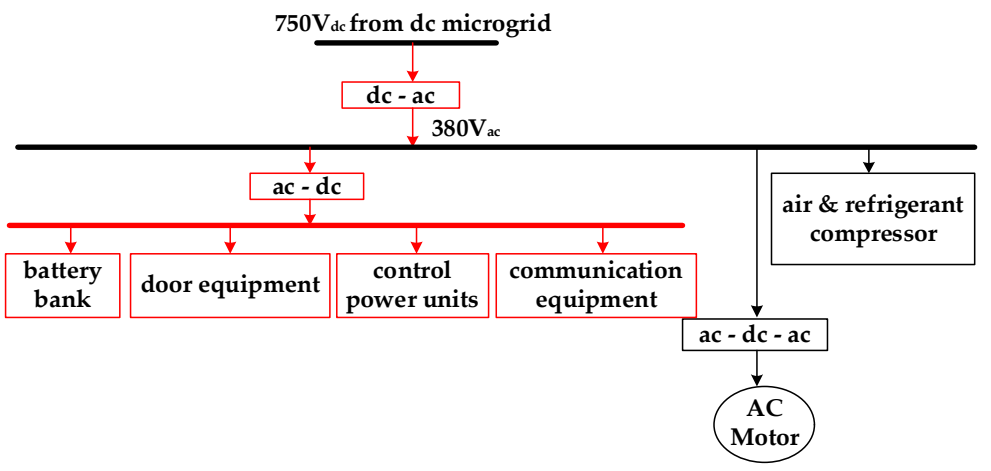

(b)

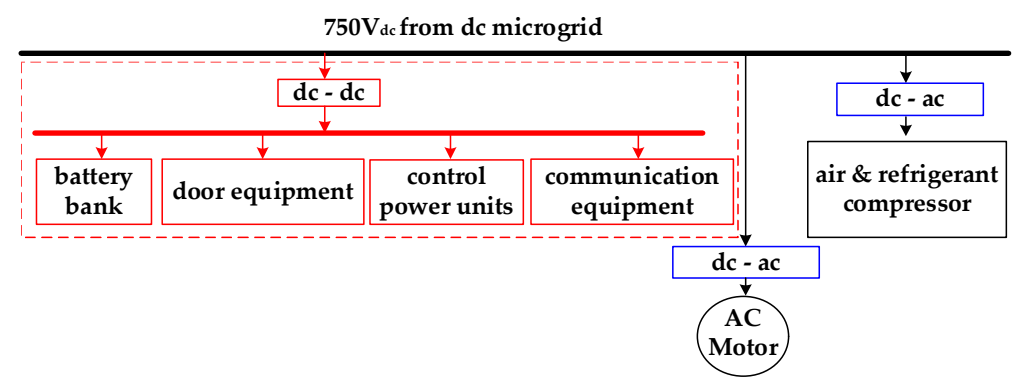

(c)

Figure 2. Basic blocks of light rail transportation vehicle (a) light rail vehicle; (b) distributed power in conventional vehicle; (c) distributed power in the studied case. 


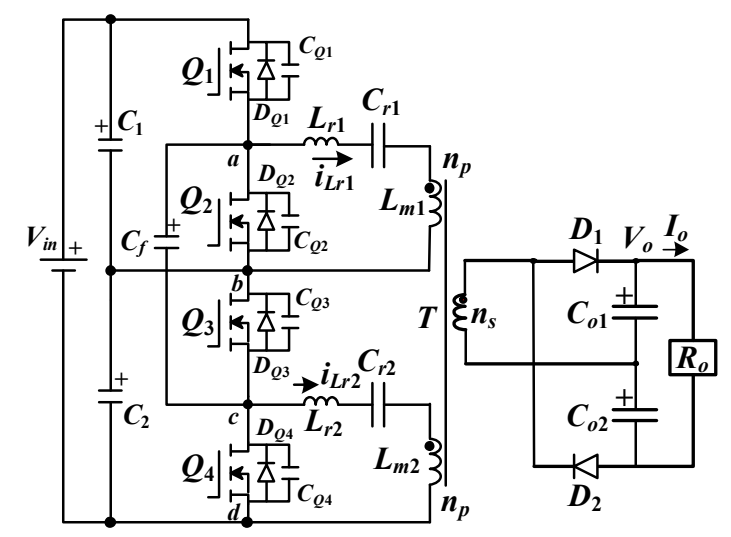

Figure 3. Proposed circuit schematic.

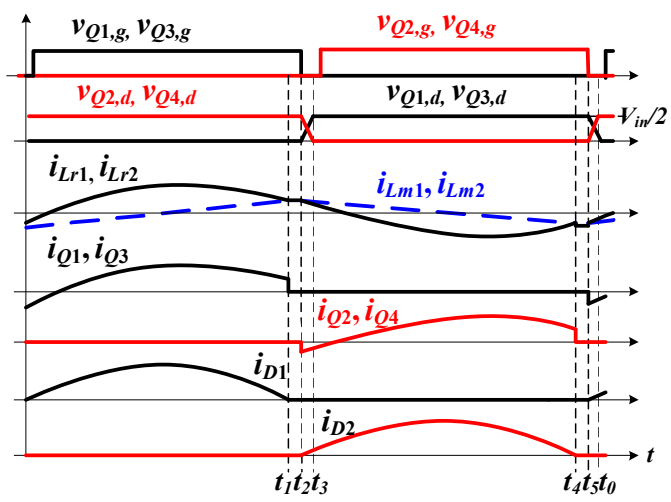

Figure 4. Basic circuit waveforms of the studied cascade resonant dc-dc converter.

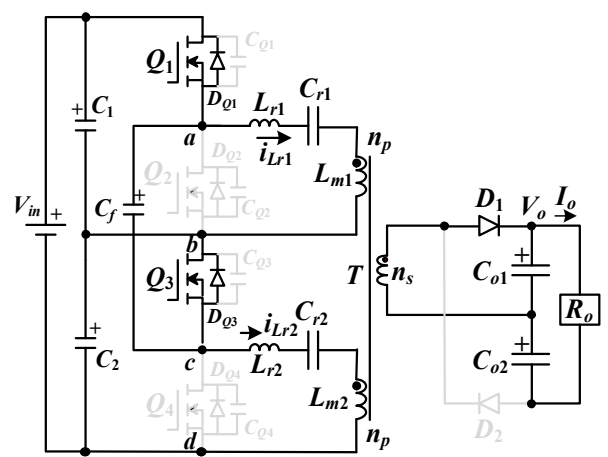

(a)

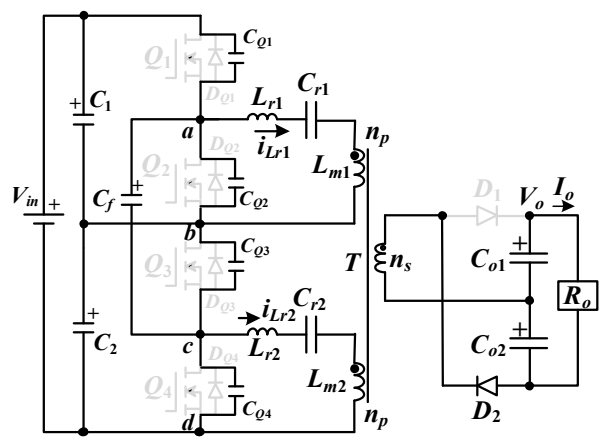

(c)

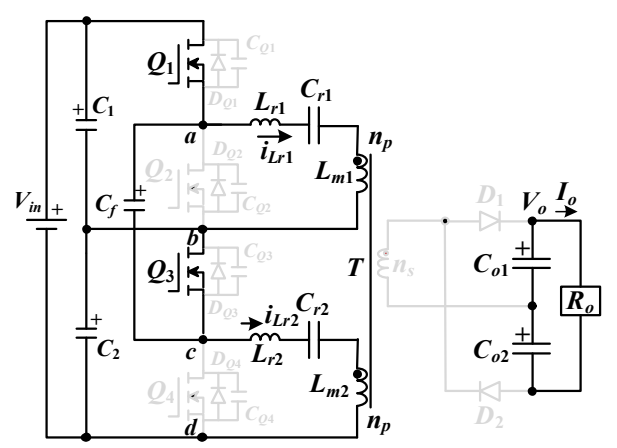

(b)

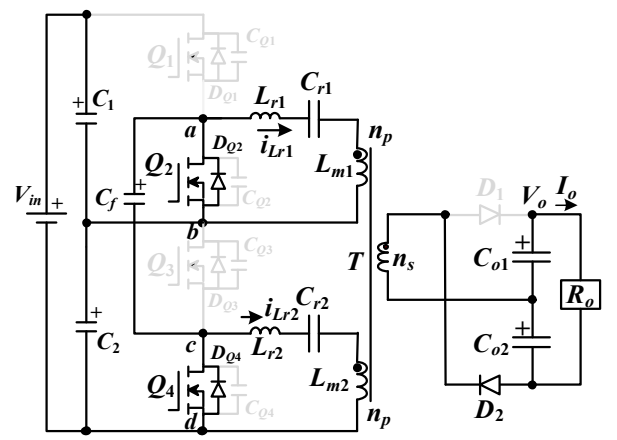

(d)

Figure 5. Cont. 


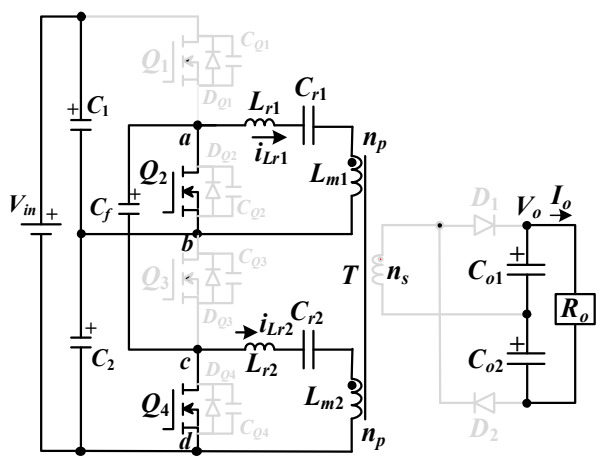

(e)

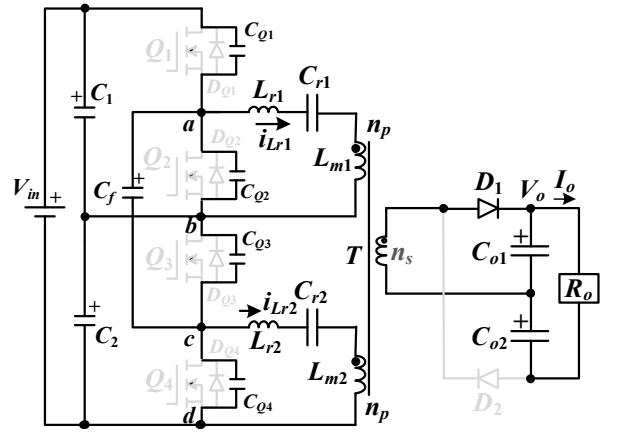

(f)

Figure 5. Equivalent circuits (a) mode 1; (b) mode 2; (c) mode 3; (d) mode 4; (e) mode 5; (f) mode 6.

Mode 1 [ $\left.t_{0} \sim t_{1}\right]$ : The voltages of $C_{Q 1}$ and $C_{Q 3}$ are reduced to zero at $t_{0}$. Then, the body diodes $D_{Q 1}$ and $D_{Q 3}$ conduct. Thus, $Q_{1}$ and $Q_{3}$ can be turned on to achieve zero voltage. In mode $1, Q_{1}, Q_{3}$, and $D_{1}$ conduct and $V_{C 1}=V_{C f}$. The primary voltages $v_{n s}=V_{C o 1}=V_{o} / 2$ and the primary voltages $v_{n p}=\left(n_{p} / n_{s}\right) V_{o} / 2=n V_{o} / 2$. Therefore, the slope of the magnetizing currents, $d i_{L m 1} / d t$ and $d i_{L m 2} / d t$, increases with $n V_{o} /\left(2 L_{m}\right)$, where $L_{m}=L_{m 1}=L_{m 2}$. The relationships of the primary currents and the secondary current are $n\left(i_{L r 1}+i_{L r 2}-i_{L m 1}-i_{L m 2}\right)=i_{D 1}$. Since $C_{r 1}=C_{r 2}, L_{r 1}=L_{r 2}, L_{m 1}=L_{m 2}$ and $V_{C 1}=V_{C 2}$, it can obtain $i_{L m 1}=i_{L m 2}$ and $i_{L r 1}=i_{L r 2}=i_{D 1} /(2 n)+i_{L m}$. In this mode, $\left(L_{r 1}\right.$ and $\left.C_{r 1}\right)$ and $\left(L_{r 2}\right.$ and $C_{r 2}$ ) are resonant with $C_{r}=C_{r 1}=C_{r 2}$ and $L_{r}=L_{r 1}=L_{r 2}$.

$$
\begin{gathered}
v_{C r 1}(t)=v_{C r 2}(t)=v_{C r}(t)=\left[V_{i n} / 2-n V_{o} / 2\right]\left[1-\cos \omega_{r}\left(t-t_{0}\right)\right]+v_{C r}\left(t_{0}\right) \cos \omega_{r}\left(t-t_{0}\right)+i_{L r}\left(t_{0}\right) Z_{r} \sin \omega_{r}\left(t-t_{0}\right) \\
i_{L r 1}(t)=i_{L r 2}(t)=i_{L r}(t)=\frac{\left[V_{i n} / 2-n V_{o} / 2-v_{C r}\left(t_{0}\right)\right] \sin \omega_{r}\left(t-t_{0}\right)}{Z_{r}}+i_{L r}\left(t_{0}\right) \cos \omega_{r}\left(t-t_{0}\right)
\end{gathered}
$$

where $f_{r}=1 / 2 \pi \sqrt{L_{r} C_{r}}, Z_{r}=\sqrt{L_{r} / C_{r}}, v_{C r}=v_{C r 1}=v_{C r 2}$ and $i_{L r}=i_{L r 1}=i_{L r 2}$. When the magnetizing currents $i_{L m 1}$ and $i_{L m 2}$ increase and equal $i_{L r 1}$ and $i_{L r 2}$ at time $t_{1}$. Diode $D_{1}$ becomes reverse biased.

Mode 2 [ $t_{1} \sim t_{2}$ ]: At $t_{1}, i_{D 1}=0$ and $D_{1}$ is reverse biased. $i_{L r 1}$ flows through $C_{1}, Q_{1}, L_{r 1}, C_{r 1}$, and $L_{m 1}$, and $i_{L r 2}$ flows through $C_{2}, Q_{3}, L_{r 2}, C_{r 2}$, and $L_{m 2}$. Since $C_{1} \gg C_{r 1}$ and $C_{2} \gg>C_{r 2}, L_{r 1}, C_{r 1}$ and $L_{m 1}$ are resonant, and $L_{r 2}, C_{r 2}$, and $L_{m 2}$ are resonant.

$$
\begin{gathered}
v_{C r 1}(t)=v_{C r 2}(t)=v_{C r}(t)=V_{i n}\left[1-\cos \omega_{p}\left(t-t_{1}\right)\right] / 2+v_{C r}\left(t_{1}\right) \cos \omega_{p}\left(t-t_{1}\right)+i_{L r}\left(t_{1}\right) Z_{p} \sin \omega_{p}\left(t-t_{1}\right) \\
i_{L r 1}(t)=i_{L r 2}(t)=i_{L r}(t)=\frac{\left[V_{i n} / 2-v_{C r}\left(t_{1}\right)\right] \sin \omega_{p}\left(t-t_{1}\right)}{Z_{p}}+i_{L r}\left(t_{1}\right) \cos \omega_{p}\left(t-t_{1}\right)
\end{gathered}
$$

where $Z_{p}=\sqrt{\left(L_{m}+L_{r}\right) / C_{r}}$ and $\omega_{p}=1 / \sqrt{\left(L_{m}+L_{r}\right) C_{r}}$.

Mode 3 [ $t_{2} \sim t_{3}$ ]: At $t_{3}$, active devices $Q_{1}$ and $Q_{3}$ turn off. $i_{L r 1}\left(t_{2}\right)$ will charge $C_{Q 1}$ and discharge $C_{Q 2}$, and $i_{L r 1}\left(t_{2}\right)$ will charge $C_{Q 3}$ and discharge $C_{Q 4}$. During this time interval, $D_{2}$ conducts and $v_{L m 1}=v_{L m 2}=-n V_{o} / 2$. Since $C_{Q 1} \sim C_{Q 4}$ are so small, the time interval is neglected and $i_{L r 1}$ and $i_{L r 2}$ are considered constant.

Mode 4 [ $\left.t_{3} \sim t_{4}\right]$ : This mode starts at $t_{3}$ if $v_{\mathrm{CQ} 1}=v_{\mathrm{C} 1}, v_{\mathrm{CQ} 3}=v_{\mathrm{C} 2}$ and $v_{\mathrm{CQ} 2}=v_{\mathrm{CQ} 4}=0$. Due to $i_{\operatorname{Lr} 1}\left(t_{3}\right)>0$ and $i_{L r 2}\left(t_{3}\right)>0, D_{Q 2}$ and $D_{Q 4}$ conduct. Therefore, active devices $Q_{2}$ and $Q_{4}$ turn on after $t_{3}$ to have the characteristic of zero voltage turn-on operation. In this mode, $v_{C f}=V_{C 2}$. Since $D_{2}$ is forward biased, $v_{L m 1}=v_{L m 2}=-n V_{o} / 2$ so that $i_{L m 1}$ and $i_{L m 2}$ decreases. $v_{C r 1}, v_{C r 2}, i_{L r 1}$, and $i_{L r 2}$ in mode 4 are calculated in (5) and (6).

$$
\begin{gathered}
v_{C r 1}(t)=v_{C r 2}(t)=v_{C r}(t)=n V_{o}\left[1-\cos \omega_{r}\left(t-t_{3}\right)\right]+v_{C r}\left(t_{3}\right) \cos \omega_{r}\left(t-t_{3}\right)+i_{L r}\left(t_{3}\right) Z_{r} \sin \omega_{r}\left(t-t_{3}\right) \\
i_{L r 1}(t)=i_{L r 2}(t)=i_{L r}(t)=\frac{\left[n V_{o}-v_{C r}\left(t_{3}\right)\right] \sin \omega_{r}\left(t-t_{3}\right)}{Z_{r}}+i_{L r}\left(t_{3}\right) \cos \omega_{r}\left(t-t_{3}\right)
\end{gathered}
$$


When $i_{L m 1}=i_{L r 1}$ and $i_{L r 2}=i_{L m 2}$ at time $t_{4}$. Diode $D_{2}$ is reverse biased.

Mode $5\left[t_{4} \leq t<t_{5}\right]$ : After $t_{4}, D_{2}$ is reverse biased and $v_{C f}=V_{C 2} . i_{L r 1}$ flows through $Q_{2}, L_{r 1}, C_{r 1}$, and $L_{m 1}$, and $i_{L r 2}$ flows through $Q_{4}, L_{r 2}, C_{r 2} ; L_{m 2} . L_{r 1}, C_{r 1}$, and $L_{m 1}$ are resonant; and $L_{r 2}, C_{r 2}$, and $L_{m 2}$ are resonant.

Mode $6\left[t_{5} \leq t<t_{0}\right]: Q_{2}$ and $Q_{4}$ turn off at time $t_{5} . i_{L r 1}\left(t_{5}\right)$ will charge $C_{Q 2}$ and discharge $C_{Q 1}$, and $i_{L r 1}\left(t_{5}\right)$ will charge $C_{Q 4}$ and discharge $C_{Q 3}$. Since $D_{1}$ is forward biased, $v_{L m 1}=v_{L m 2}=n V_{o} / 2$. At $t_{0}$, $v_{C Q 1}=v_{C Q 3}=0$.

\section{Circuit Characteristics, Design Example, and Test Results}

If active devices $Q_{1}$ and $Q_{3}$ conduct as shown in Figure 6a, it obtains $v_{C f}=V_{C 1}$. If $V_{C 1}$ is greater (or less) than $V_{C 2}$, then $C_{1}$ will charge (or discharge) $C_{f}$ via active devices $Q_{1}$ and $Q_{3}$. In a similar way, $v_{C f}$ is equal to $V_{C 2}$ if active devices $Q_{2}$ and $Q_{4}$ conduct as shown in Figure $6 \mathrm{~b}$. If $V_{C 1}$ is greater (or less) then $V_{C 2}, C_{f}$ will charge (or discharge) $C_{2}$ via active devices $Q_{2}$ and $Q_{4}$. Therefore, $V_{C 1}$ and $V_{C 2}$ are controlled to be balanced at $V_{\text {in }} / 2$. Fundamental frequency analysis is selected to analyze the transfer function of the studied circuit. The primary inductor voltages $v_{L m 1}=v_{L m 2}=n V_{o} / 2$. According to fundamental harmonic frequency analysis, the equivalent ac resistance is calculated in (7).

$$
R_{a c}=R_{a c, 1}=R_{a c, 2}=\frac{4 n^{2}}{\pi^{2}} R_{o}
$$

Based on the voltage divider of the resonant tank by $C_{r 1}, L_{r 1}, L_{m 1}$, and $R_{a c 1}$, the voltage gain of the resonant circuit is calculated in (8).

$$
\left|G_{a c}(f)\right|=\frac{1}{\sqrt{\left[1+\frac{1}{m}\left(1-\frac{f_{r}^{2}}{f_{s w}^{2}}\right)\right]^{2}+Q^{2}\left(\frac{f_{s w w}}{f_{r}}-\frac{f_{r}}{f_{s w}}\right)^{2}}}
$$

where $m=L_{m} / L_{r}$ and $Q=\sqrt{L_{r} / C_{r}} / R_{a c}$.

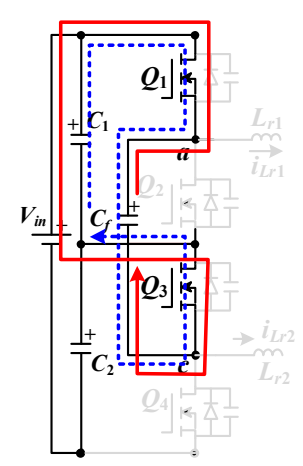

(a)

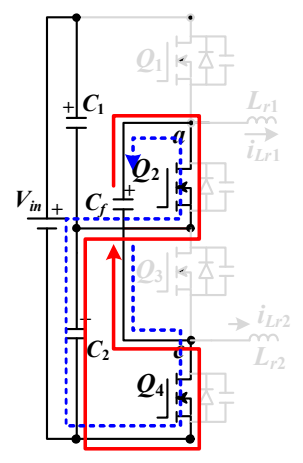

(b)

Figure 6. Voltage-balancing by flying capacitor (a) Q1 and Q3 on (b) Q2 and Q4 on.

The electrical specifications of the proposed circuit in a laboratory prototype are: $V_{\text {in }}=750 \mathrm{~V} \sim 800 \mathrm{~V}$, $V_{o}=48 \mathrm{~V}, I_{0, \max }=21 \mathrm{~A}$, and series resonant frequency $f_{r}=100 \mathrm{kHz}$. The unity DC gain of resonant circuit is designed at $V_{\text {in }}=800 \mathrm{~V}$. The turn-ratio of $T$ is expressed in (9).

$$
n=\frac{V_{i n, \max }}{2 V_{o}}=\frac{800}{2 \times 48} \approx 8.33
$$

The magnetic core TDK EER-42 (TDK Corporation, Tokyo, Japan) with $A_{e}=1.94 \mathrm{~cm}^{2}$ is selected for transformer with $n_{p}=25$ turns and $n_{s}=3$ turns. Then the maximum DC voltage gain at $V_{\text {in }}=750 \mathrm{~V}$ is obtained in (10). 


$$
G_{d c, \max }=\frac{2 n V_{o}}{V_{i n, \min }}=\frac{2 \times 8.33 \times 48}{750} \approx 1.066
$$

From (7), $R_{a c}$ under full load is derived in (11).

$$
R_{a c}=\frac{4 n^{2}}{\pi^{2}} R_{o, \text { rated }}=\frac{4 \times 8.33^{2}}{\pi^{2}} \times \frac{48}{21} \approx 64.28 \Omega
$$

The selected inductor ratio $m=L_{m} / L_{r}=10$ and quality factor $Q=0.3$. From the given $Q=0.3$ at full load and $f_{r}=100 \mathrm{kHz}$, the series resonant inductors and resonant capacitors are obtained in (12) and (13).

$$
\begin{gathered}
L_{r 1}=L_{r 2}=\frac{R_{a c} Q}{2 \pi f_{r}}=\frac{64.28 \times 0.3}{2 \pi \times 100,000} \approx 31 \mu \mathrm{H} \\
C_{r 1}=C_{r 2}=\frac{1}{4 \pi^{2} L_{r} f_{r}^{2}}=\frac{1}{4 \pi^{2} \times 57 \times 10^{-6} \times(100,000)^{2}} \approx 82 n F
\end{gathered}
$$

The magnetizing inductances $L_{m 1}$ and $L_{m 2}$ are obtained in (14).

$$
L_{m 1}=L_{m 2}=m \times L_{r}=10 \times 31=310 \mu H
$$

The current and voltage ratings of $C_{r 1}$ and $C_{r 2}$ are obtained in (15) and (16).

$$
\begin{gathered}
i_{C r 1, r m s}=i_{C r 2, r m s}=\sqrt{\left(\frac{\pi I_{o, \max }}{2 n \sqrt{2}}\right)^{2}+\left(\frac{n V_{o} / 2}{4 \sqrt{3} L_{m 1} f_{r}}\right)^{2}} \approx 2.95 \mathrm{~A} \\
v_{C r 1, \max }=v_{C r 2, \max }=V_{i n, \max } / 2+\sqrt{2} i_{C r, r m s} /\left(2 \pi f_{r} C_{r}\right) \approx 281 \mathrm{~V}
\end{gathered}
$$

The average current and voltage ratings of fast recovery diodes are expressed in (17) and (18).

$$
\begin{gathered}
i_{D 1, a v}=i_{D 2, a v}=I_{o} / 2=10.5 \mathrm{~A} \\
v_{D 1, \text { stress }}=v_{D 2, \text { stress }}=V_{o}=48 \mathrm{~V}
\end{gathered}
$$

Diodes MBR40200PT are selected for $D_{1}$ and $D_{2}$ in the studied converter. The voltage rating of $Q_{1} \sim Q_{4}$ equals $V_{\text {in }} / 2=400$ V. MOSFETs G20N50C (Vishay Dale Electronics Inc., Pennsylvania, USA) with $500 \mathrm{~V}$ voltage stress instead of $1200 \mathrm{~V}$ IGBT are used for $Q_{1} \sim Q_{4}$. The other capacitors $C_{1}=C_{2}=$ $220 \mu \mathrm{F}, C_{f}=2.2 \mu \mathrm{F}$, and $C_{01}=C_{02}=2200 \mu \mathrm{F}$. A type 2 voltage controller with a shunt voltage regulator based on the TL431 and a photocoupler based on PC817 are used to achieve output voltage control. The frequency control IC with Texas Instruments UCC25600 is selected to control $Q_{1} \sim Q_{4}$.

A $1 \mathrm{~kW}$ circuit was built and the test results are demonstrated to show the performance of the studied converter. The circuit components of the proposed circuit are obtained from previous section. Figure $7 \mathrm{a}$ gives the photograph of the proposed prototype and Figure $7 \mathrm{~b}$ gives the block diagram of the experimental circuit model. The test waveforms shown in Figures 8-13 of the converter is supplying $1 \mathrm{~kW}$ of output power under $V_{\text {in }}=750 \mathrm{~V}$. The PWM signals of $Q_{1} \sim Q_{4}$ of $50 \%$ load and $100 \%$ load are shown in Figure 8. The switching frequency at $100 \%$ load is less than the frequency at $50 \%$ load. Figure 9 demonstrates the measured waveforms of $V_{C 1}, V_{C 2}$, and $V_{C f}$ at $50 \%$ load and $100 \%$ load. The test experimental waveforms of $V_{C 1}, V_{C 2}$, and $V_{C f}$ are balanced. Figure 10 gives the test waveforms of $v_{C r 1}, v_{C r 2}, i_{L r 1}$, and $i_{L r 2}$ at $50 \%$ and $100 \%$ loads. The test results show that $v_{C r 1}$ and $v_{C r 2}$ are balanced and $i_{L r 1}$ and $i_{L r 2}$ are balanced. Figure 11 demonstrates the measured $i_{D 1}, i_{D 2}, i_{D 1}+i_{D 2}$ and $V_{o}$ at $50 \%$ and $100 \%$ loads. It is observed that the zero-current turn-off of $D_{1}$ and $D_{2}$ are realized. Figure 12 demonstrates the measured voltage and current of $Q_{1} \sim Q_{4}$ at $20 \%$ load. It can observe that $C_{Q}$ is discharged to zero voltage before switch $Q$ is active. It can also observe that the voltage stress of each active devices is equal to $V_{\text {in }} / 2=375 \mathrm{~V}$ instead of $V_{\text {in }}=750 \mathrm{~V}$. Since power devices with low voltage stress are used in the studied converter, the conduction losses due to turn-on resistance of MOSFETs are 
reduced. Therefore, the power losses on power devices are improved. Figure 13a the measured circuit efficiencies of the proposed converter and the conventional three-level phase-shift PWM converter with the same power devices, capacitors, and core size as the proposed converter. This three-level PWM converter have been built in the laboratory for many years to study high input voltage applications. The circuit efficiencies of the proposed converter from $92.3 \%$ (at $20 \%$ load) to $95.4 \%$ (at $75 \%$ load) under $750 \mathrm{~V}$ input. The measured circuit efficiencies of the conventional three-level PWM converter are from $90 \%$ (at $20 \%$ load) to $92 \%$ (at $75 \%$ load). It is clear that the proposed converter has better circuit efficiency. The main reasons of the low circuit efficiency of the conventional three-level PWM converter are high duty loss on heavy load (75\% load and 100\% load) and high switching frequency at light load (20\% load). However, the switching loss on the proposed converter from low load to full load can be removed due to resonant behavior. Figure $13 \mathrm{~b}$ gives the measured circuit efficiencies and the frequency range is from $62 \mathrm{kHz}$ to $78 \mathrm{kHz}$ at $750 \mathrm{~V}$ input and from $95 \mathrm{kHz}$ to $123 \mathrm{kHz}$ at $800 \mathrm{~V}$ input case.

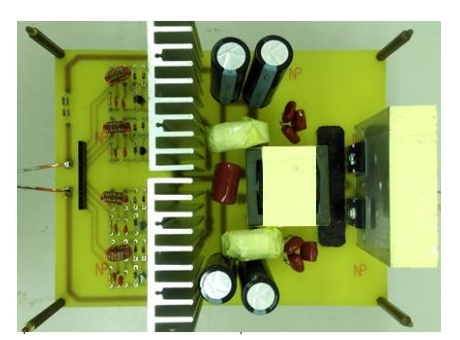

(a)

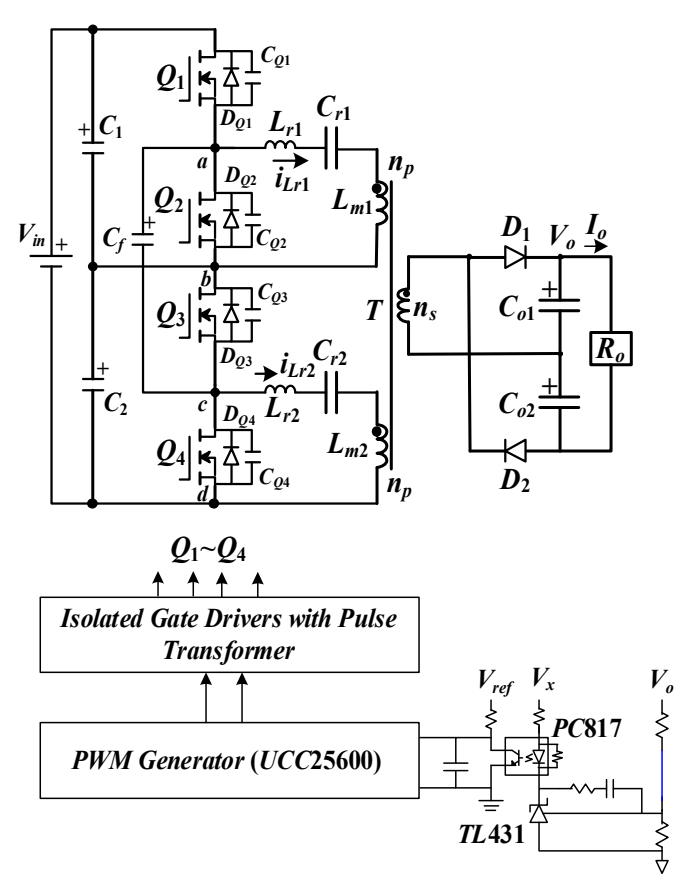

(b)

Figure 7. Proposed prototype circuit (a) photograph and (b) block diagram.

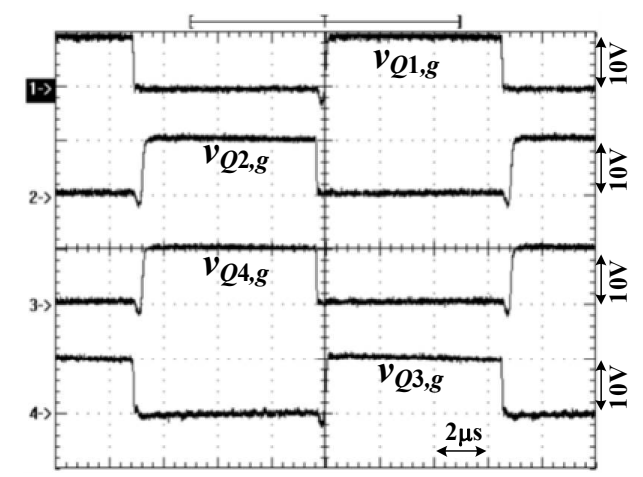

(a)

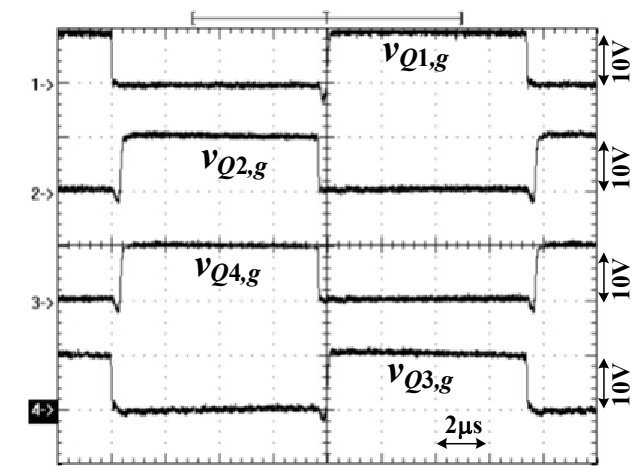

(b)

Figure 8. Test results of $v_{Q 1, g} \sim v_{Q 4, g}$ at (a) $50 \%$ power and (b) rated power. 


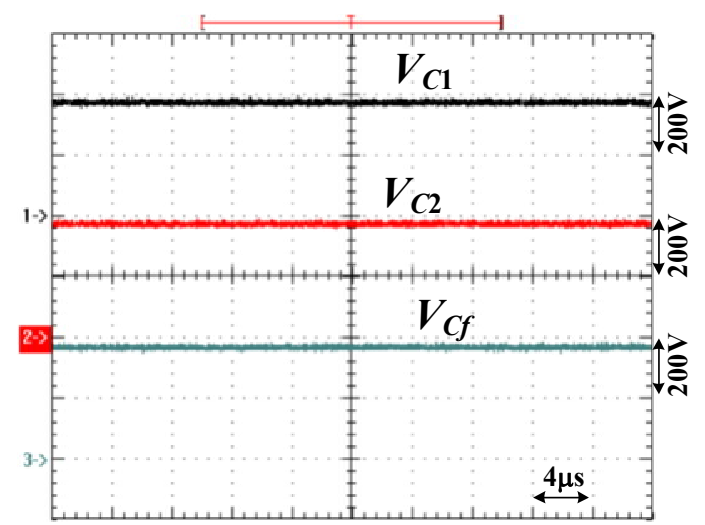

(a)

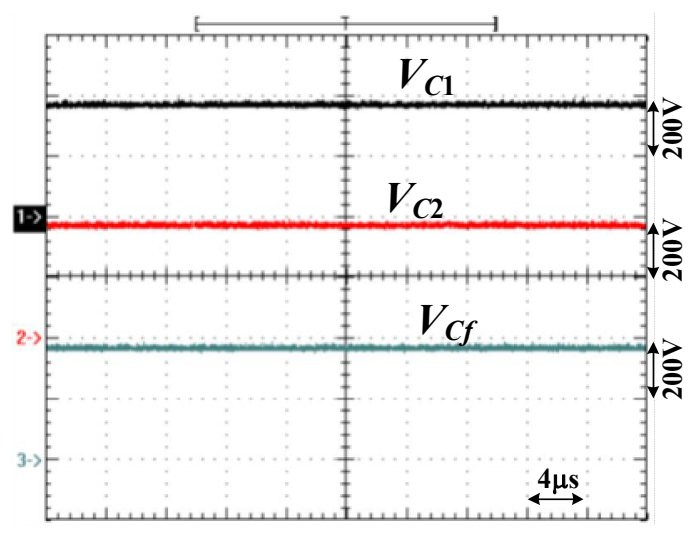

(b)

Figure 9. Experimental waveforms of $V_{C 1}, V_{C 2}$, and $V_{C f}(\mathbf{a})$ at $50 \%$ power and (b) rated power.

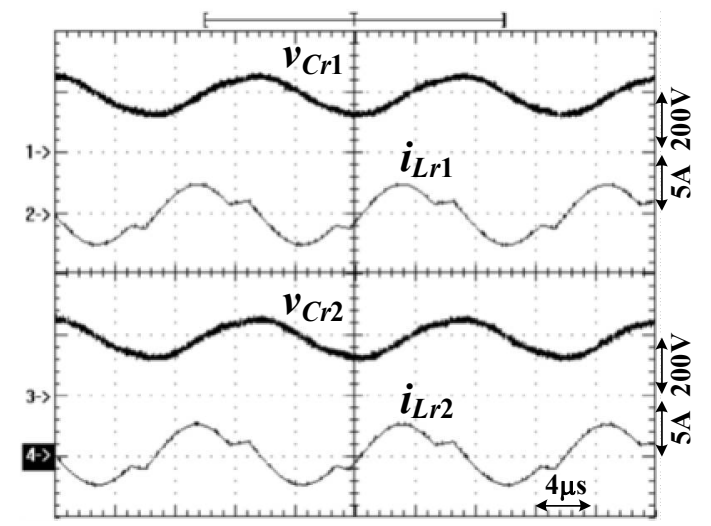

(a)

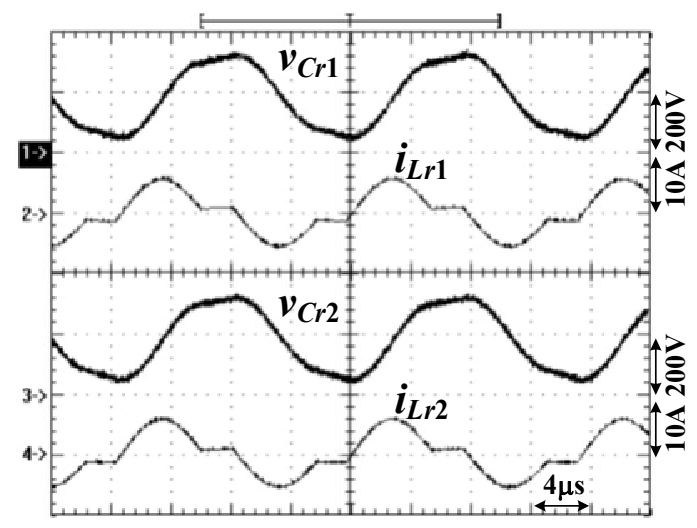

(b)

Figure 10. Experimental waveforms of $v_{C r 1}, v_{C r 2}, i_{L r 1}$, and $i_{L r 2}(\mathbf{a})$ at $50 \%$ power and (b) rated power.

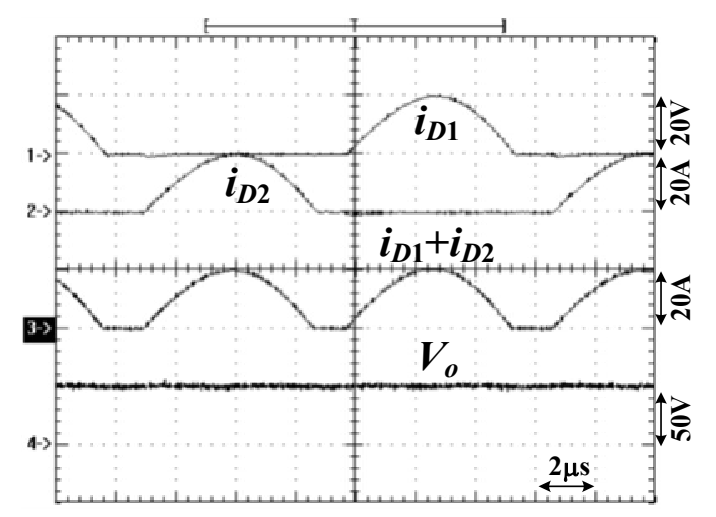

(a)

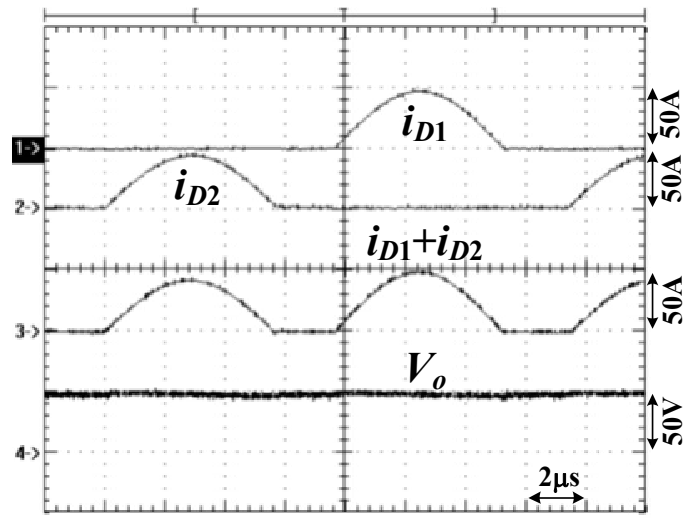

(b)

Figure 11. Test waveforms of diode currents and output voltage (a) at $50 \%$ power and (b) rated power. 


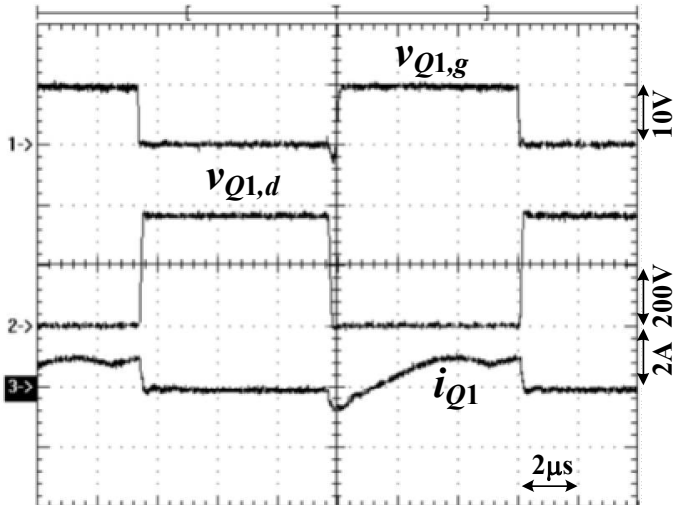

(a)

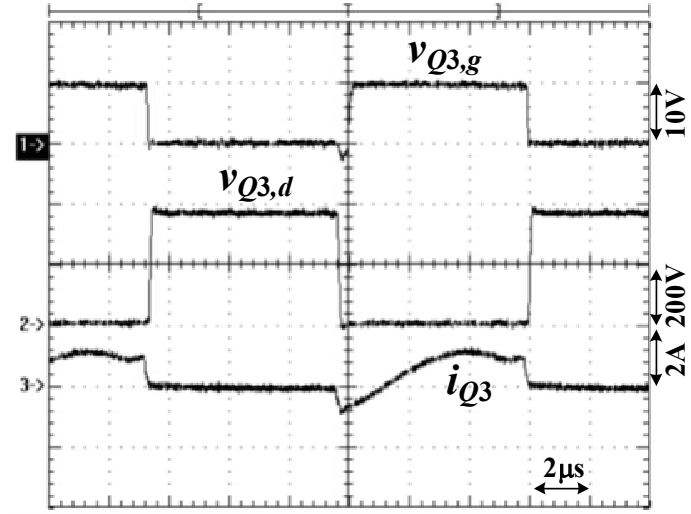

(c)

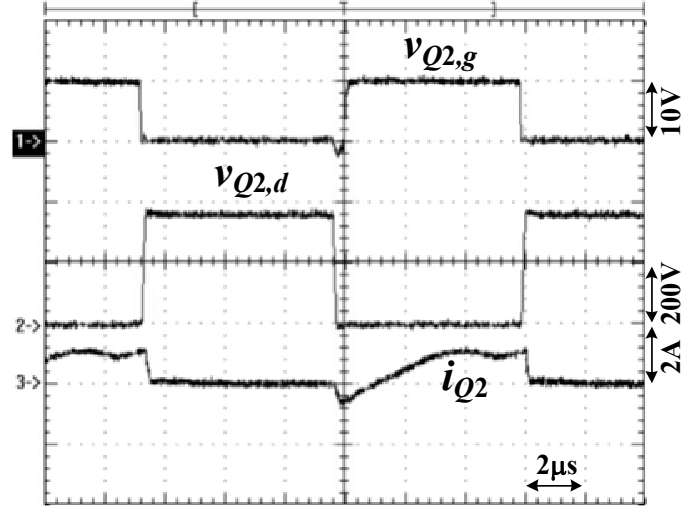

(b)

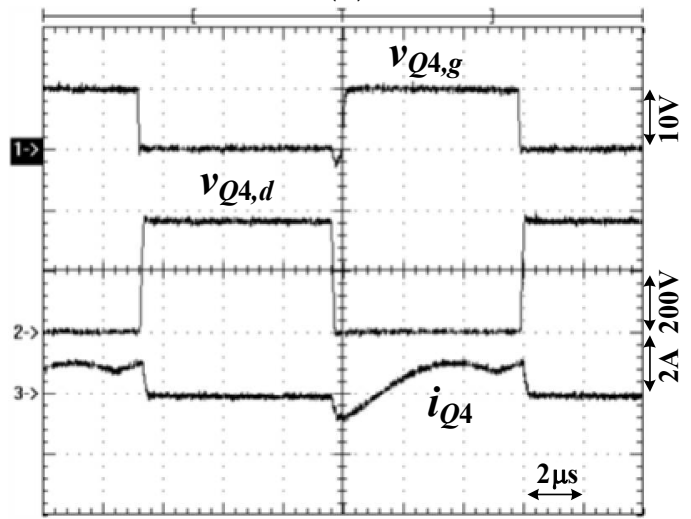

(d)

Figure 12. Commutation of switches $Q_{1} \sim Q_{4}$ under $20 \%$ load (a) $Q_{1} ;$ (b) $Q_{2} ;$ (c) $Q_{3} ;$ (d) $Q_{4}$.

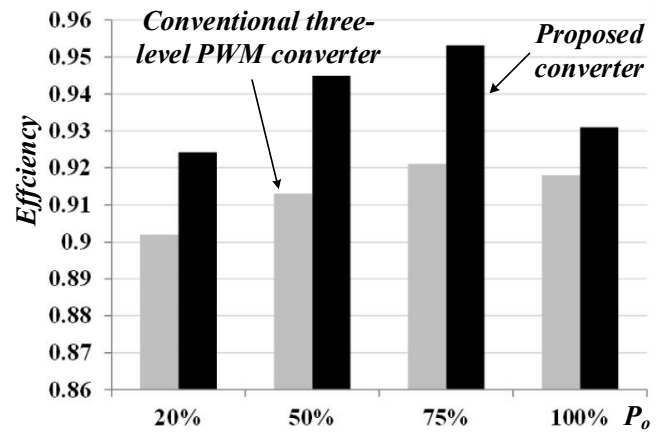

(a)

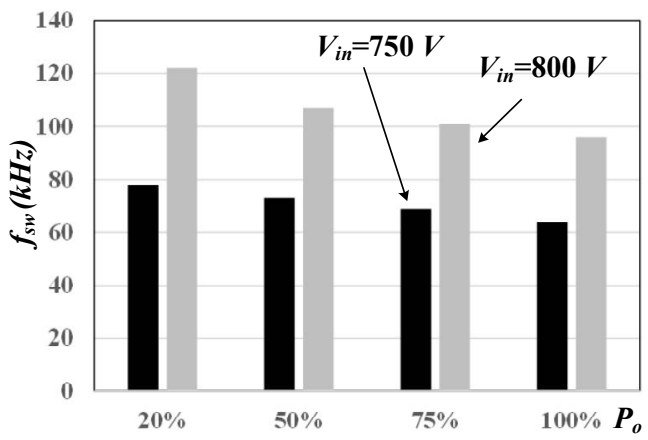

(b)

Figure 13. Test results (a) circuit efficiency compared to the conventional three-level PWM converter; (b) switching frequency.

\section{Conclusions}

A cascade resonant circuit with a single isolated transformer feasible to transportation vehicle applications is studied and presented in this paper. The circuit schematic, principles of operation and design procedure of the developed circuit are provided and discussed. Although the high voltage 1200 V SiC (Silicon Carbide) MOSFETs can be used on phase-shift full-bridge converter, the narrow ZVS range of lagging-leg switches will result in low circuit efficiency at low load. The cost of $1200 \mathrm{~V}$ $\mathrm{SiC}$ MOSFETs is main drawback to implement power products with low cost and high quality power supply. Therefore, lots of three-level circuit topologies are still developing to overcome the high voltage input issue. The benefits of the adopted circuit are low voltage rating of power semiconductor devices, 
less power loss, and better efficiency. Finally, the practicability of the adopted power converter are demonstrated from a laboratory circuit under $1 \mathrm{~kW}$ rated power.

Author Contributions: B.R. Lin designed the main parts of the project and was also responsible for writing the paper.

Acknowledgments: This study is funding by the Ministry of Science and Technology, Taiwan, under contract MOST 105-2221-E-224-043-MY2. Author thanks Guan-Yi Wu for his help to build the circuit and measured the experimental waveforms.

Conflicts of Interest: The author declares no potential conflict of interest.

\section{References}

1. Barrero, R.; Mierlo, J.V.; Tackoen, X. Energy saving in public transport. IEEE Veh. Technol. Mag. 2008, 3, 26-36. [CrossRef]

2. Chaudhary, P.; Samanta, S.; Sesarma, P. Input-series-output-parallel-connected buck rectifiers for high-voltage applications. IEEE Trans. Ind. Electron. 2015, 62, 193-202. [CrossRef]

3. Chua, T.Z.Y.; Ong, Y.T.; Toh, C.L. Transformerless DC traction power conversion system design for light-rail-transit (LRT). In Proceedings of the IEEE Conference on Energy Conversion (CENCON), Kuala Lumpur, Malaysia, 30-31 October 2017; pp. 38-43.

4. Akagi, H. Classification, terminology, and application of the modular multilevel cascade converter (MMCC). IEEE Trans. Power Electron. 2011, 26, 3119-3130. [CrossRef]

5. Lee, J.P.; Min, B.D.; Kim, T.J.; Yoo, D.W.; Yoo, J.Y. Input-Series-Output-Parallel Connected DC/DC Converter for a Photovoltaic PCS with High Efficiency under a Wide Load Range. J. Power Electron. 2010, 10, 9-13. [CrossRef]

6. Tao, X.; Li, Y.; Sun, M. A pi-based control scheme for primary cascaded H-bridge rectifier in transformerless traction converters. In Proceedings of the International Conference on Electrical Machines and Systems (ICEMS), Incheon, South Korea, 10-13 October 2010; pp. 824-828.

7. Liu, W.; Jin, H.; Yao, W.; Lu, Z. An interleaved PWM method with voltage-balancing ability for half-bridge three-level converter. IEEE Trans. Power Electron. 2018, 33, 4594-4598. [CrossRef]

8. Lin, B.R. Interleaved zero-voltage switching three-level converter with less output inductor counts. IET Proc. Power Electron. 2017, 10, 707-716. [CrossRef]

9. Song, W.; Ma, J.; Zhou, L.; Feng, X. Deadbeat predictive power control of single-phase three-level neutral-point-clamped converters using space-vector modulation for electric railway traction. IEEE Trans. Power Electron. 2016, 31, 721-732. [CrossRef]

10. Mallik, A.; Khaligh, A. Variable-switching-frequency state-feedback control of a phase-shifted full-bridge dc/dc converter. IEEE Trans. Power Electron. 2017, 32, 6523-6531. [CrossRef]

11. Kim, J.W.; Kim, D.Y.; Kim, C.E.; Moon, G.W. A simple switching control technique for improving light load efficiency in a phase-shifted full-bridge converter with a server power system. IEEE Trans. Power Electron. 2014, 29, 1562-1566. [CrossRef]

12. Kundu, U.; Pant, B.; Sikder, S.; Kumar, A.; Sensarma, P. Frequency domain analysis and optimal design of isolated bidirectional series resonant converter. IEEE Trans. Ind. Appl. 2018, 54, 356-366. [CrossRef]

13. Hiroyuki, H.; Kurokawa, F. Modulation method of a full-bridge three-level LLC resonant converterfor battery charger of electrical vehicles. IEEE Trans. Power Electron. 2017, 32, 2498-2507.

(C) 2018 by the author. Licensee MDPI, Basel, Switzerland. This article is an open access article distributed under the terms and conditions of the Creative Commons Attribution (CC BY) license (http://creativecommons.org/licenses/by/4.0/). 